\title{
Corela
}

Cognition, représentation, langage

HS- 19 | 2016

Le point de vue pris au mot

\section{Cognitive Systems, Semantic Constraints and Fragmented Narratives in the Digital Age}

\section{László I. Komlósi}

\section{(2) OpenEdition}

\section{Journals}

\section{Édition électronique}

URL : http://journals.openedition.org/corela/4315

DOI : $10.4000 /$ corela.4315

ISSN : 1638-573X

\section{Éditeur}

Cercle linguistique du Centre et de I'Ouest - CerLICO

\section{Référence électronique}

László I. Komlósi, « Cognitive Systems, Semantic Constraints and Fragmented Narratives in the Digital Age », Corela [En ligne], HS-19 | 2016, mis en ligne le 08 juin 2016, consulté le 30 avril 2019. URL : http://journals.openedition.org/corela/4315; DOI : 10.4000/corela.4315

Ce document a été généré automatiquement le 30 avril 2019.

\section{(c) (i) (2)(2)}

Corela - cognition, représentation, langage est mis à disposition selon les termes de la licence Creative Commons Attribution - Pas d'Utilisation Commerciale - Partage dans les Mêmes Conditions 4.0 International. 


\title{
Cognitive Systems, Semantic Constraints and Fragmented Narratives in the Digital Age
}

\author{
László I. Komlósi
}

\section{Captatio benevolentiae}

1 A scholar can be considered privileged if they can test the results of their scientific endeavor with colleagues of similar interests but diverse approaches and methods. An even greater gift is a situation in which you can test the ideas of your fellow scholars in vivid, argumentative discussions. I owe a lot in my professional career to Pierre-Yves Raccah both in terms of acquainting myself with his writings and conducting intensive discussions with him about empiricity for semantics, linguistic constraints in argumentation, observation and point of view, only to name a few of the topics of our disputes. Many things have stimulated and intrigued me in Pierre-Yves' arguments, notwithstanding that they may have remained unclear or unanswered to me despite the numerous years we have collaborated in the activities of ISSA and on several conferences in Hungary. It was my deeper interest in cognitive systems (cognitive language system, cognitive culture system) and language-culture parallelism that has facilitated my understanding of Pierre-Yves' intended senses of semantics, argumentation and point of view

2 In what follows I intend to share some of these revelations which are the result of my privileged situation of having semi-direct access to Pierre-Yves' point of view on the crucial properties of natural language, especially on the semantic constraints on the construction and interpretation of the meaning of the utterances.

My linguistic interest has found manifestation in the study of formal semantics and lexical semantics (Komlósi 2013) on the one hand and speech acts, context-dependence, inferential reasoning and argumentation (Komlósi 2003, 2006, 2007) on the other. It may strike many that linguistic meaning (sentence meaning based on computed linguistic 
structure) and utterance meaning (constructed interpretations based on pragmatically determined contexts of utterance) have been dealt with in mainstream linguistics under very different theoretical presumptions. And still, one has to admit that both language and speech fall under the scope of the Language Faculty, thus constituting and facilitating linguistic cognition.

How should one bridge the alleged difference between semantics as a conceptual framework for linguistic meaning and pragmatics as a conceptual framework for contextualized utterance meaning?

In my analysis I will discuss two, seemingly antagonistic approaches to semantics : one assumes semantics to be a non-cognitive, objective tool to facilitate the inter-subjective construction of utterance interpretations in the interlocutors, the other one assumes semantics to be a language specific manifestation of concept structuring in linguistic cognition. My discussion has been conceived in the intention to point at a possible platform for reconciliation between the two views on semantics by re-conceptualizing the notion "constraints on meaning construction" used as a foundational construct underlying the arguments of both approaches under scrutiny. I will argue that it is the conceptual frameworks associated with different high-level and complex cognitive systems (such as the cognitive language system and the cognitive culture system) which get constrained by linguistic structure and linguistic meaning of natural languages on the one hand and cultural structure of human social institutions and social behavior patterns on the other.

\section{Semantic constraints on argumentation and View- Point Semantics by Pierre-Yves Raccah}

In his seminal paper Pierre-Yves Raccah (2005) put forward strong arguments for an empirical theory of linguistics in which he states that we can have empirical, although indirect observations related to semantics by observing utterances and / or behavior.

We will see that these semantic rules have to be seen as re-constructions, by the observers, of processes of sense construction, in which the meanings of sentences are the tools which operate on the hearer's knowledge for her / him to build an interpretation of the utterance of the sentence, in the situation in which it was uttered. In that sense, though semantics is obviously related to cognitive science, its objects of study are not cognitive objects. (Raccah $2005: 52$ )

In his view, semantics is the study of what in the structure of human languages directly contributes to the construction of the meaning of utterances. This contribution takes effect in imposing constraints on the senses of utterances. Raccah expands the notion of constraint to any scientific theory and claims that the role of scientific theories (a semantic theory included) is not to explain phenomena but to provide constrained descriptions such that the interpretation of phenomena (in linguistics the senses of utterances) get to be channeled and controlled. Further, the communal aspect is underlined by the author as he emphasizes that once a scientific theory is accepted by the community, it constitutes an inter-subjective tool to perceive and interpret phenomena. Such framework conditions of interpretation secure societal interpretative practices in which interpretations often rely on previously admitted scientific or non-scientific (naïve) theories (Raccah 2005 : 62-63). How the "objective" turns into "inter-subjective" in the process of utterance interpretation, can be explained if we find the nature of the 
relationship between theories of language structure and the theories of cognition. I will attempt to reconstruct (in my own interpretation) the conceptual analyses of "semantic objects" and "cognitive objects" as used in Raccah's semantic theory.

One may wonder what the nature of these constraints in the case of semantic contribution to linguistic meaning might be. Raccah's choice is to identify such constraints with descriptions of the semantic argumentative features of a sentence derived from the semantic description of the words of that sentence. It is of great importance to realize that lexical items not only acquire and exert power to impose constraints on utterance interpretation but they also link up to the fundamental elements of human expertise shared in the speech communities. Raccah (2005: 69) illustrates and defends three related claims here :

- lexical items impose biases on their denotation;

- these biases capture an important part of the beliefs and knowledge of the

linguistic community who share these lexical items ;

- human expertise strongly relies on this kind of knowledge.

Thus, these descriptions are utterance independent since they concern the constraints that language imposes on the interpretation of the utterances. Raccah goes as far as to claim that these semantic descriptions facilitate the computation of the ideological force of certain words in utterances as well (Raccah $2005: 78$ ).

10 A further enrichment of the conceptual framework of the linguistic constraints on argumentation has been achieved by subsequent research of the author which focuses and elaborates on the fine-grained semantic structure for points of view (Raccah 2007, 2011). Raccah's analysis is convincing in that the semantic description of human languages must also include the description of the constraints that words and expressions impose on the possible argumentative orientation and argumentative force of utterances containing those words and expressions. He argues that the argumentative orientation and argumentative force of an utterance should be considered as parts of its utterance meaning and understood as a point of view defended by the utterance. There are two kinds of point of view in Raccah's elaboration:

- a point of view that results from the interpretation of an utterance ;

- a point of view that must be met in order to understand an utterance ${ }^{1}$.

11 Pierre-Yves Raccah has decided to develop the intellectual scope of his semantic theory (semantic constraints on argumentation and View-Point Semantics) to new domains in (Raccah 2015). The focus of his novel endeavor is the empirical study of the relationship between argumentation and institutional constraints. He admits the ambition of his program to use semantics in order to access institutional knowledge within the study of strategic manoeuvring in a more formal and more empirical fashion. In this study he takes into account the institutional preconditions prevailing in the communicative practice. These are preconditions which can be observed through discourses (i.e. coherent sets of utterances). He makes an attempt to extract those preconditions out of stretches of discourse in order to limit the role of intuition. Thus, he finds it necessary to adopt a semantic model which can determine the contribution of language units to the assessment of those preconditions. 


\title{
2. Semantics for concept structuring in natural languages by Leonard Talmy
}

12 Leonard Talmy is a born empirical linguist and a devoted cognitivist who has proposed a novel use of the notion cognitive semantics only to support and facilitate an integrated understanding of conceptual structure manifest in human cognition, and specifically in linguistic cognition.

13 The most comprehensive work to reflect his highly affluent and productive research on concept structuring systems and processes in concept structuring is (Talmy 2000a, 2000b). Although his over-arching interest in human cognition involves the analysis of different cognitive systems (highly organized cognitive constructs underlying language, culture, learning and adaptive skills and competences, etc.), the most profound and detailed analysis concerns the study of the linguistic representation (manifestation) of conceptual structure. For this end he adopts the cognitive linguistics paradigm within a larger framework of approaches which all - in some ways - address the content-related portion of natural language. In his view, fundamentally three approaches can be designated in this respect :

- the formal;

- the psychological;

- the conceptual, which need to be addressed in relationship to each other in the linguistic system.

14 Talmy convincingly argues for the notion "semantics" as a new term in support of his particular conceptual approach (Talmy 2000a). The novel use of the term semantics is to reflect Talmy's view on semantics which is specifically concerned with (and is responsible for) the conceptual organization of natural languages. We can see in Talmy's own formulation that the role of semantics in shaping linguistic meaning is decisive and constitutive by effect of imposing constraints on conceptual organization in language.

\begin{abstract}
Semantics simply pertains to conceptual content as it is organized in language. Hence, the word "semantic" simply refers to the specifically linguistic form of the more generic notion "conceptual". Thus, general conception - that is, thought includes linguistic meaning within its greater compass. And while linguistic meaning - whether that expressible by an individual language or by language in general - apparently involves a selection from or constraints on general conception, it is qualitatively of a piece with it. (Talmy 2000a : 4)
\end{abstract}

15 It is very important to call attention to a particular feature of Talmy's cognitivism. The term "cognitive" is understood by many as a term referring to "cognitive states", or - less frequently - "mental states" reflecting belief systems and different types of knowledge which are assumed to be cognitively accessible to consciousness or possible to be brought to awareness. In his endeavor he talks about the nature of conceptual content and conceptual organization. In his view, conceptual content encompasses both ideational (i.e. concept-based) content and experiential content, including affect (i.e. emotional state) and perception. This is clearly a phenomenological approach, as witnessed in his own formulation:

Cognitive semantics centers its research on conceptual organization, hence, on content experienced in consciousness. That is, for cognitive semantics the main object of study itself is qualitative mental phenomena as they exist in awareness. Cognitive semantics is thus a branch of phenomenology, specifically, the 
phenomenology of conceptual content and its structure in language. (Talmy 2000a :

4)

16 It is worth emphasizing that the qualitative mental phenomena as they exist in awareness are known to be subjectively present. As a consequence, the phenomenological conception of cognitive semantics assumes accessibility to the subjective contents of consciousness in shaping linguistic meanings, and ultimately, organizing conceptual structure in language.

\subsection{Force-dynamic principles in concept structuring by Leonard Talmy}

Another fascinating outcome of Talmy's research on concept structuring is the recognition that force-dynamics figures significantly in language structure and plays a structuring role on several language levels, such as the lexicon (cf. "causation"), grammar or modals. Lexical items may refer to physical force interactions ("The ball kept rolling", "The wind pushed the door open") and - by metaphorical extension - to psychological force interactions ("John refrained from saying anything and kept silent", "We made him / had him / got him to rewrite the application") or socio-psychological force interactions ("She ought to behave civil to her parents"). The latter type of force interaction is often conceived in terms of "psychological or group pressure". What concerns our interest in the present paper emphatically is Talmy's observations concerning the concept structuring role of force-dynamics in discourse and argumentation. In his view, forcedynamic principles operate preeminently in directing patterns of argumentation and discourse expectations or their reversal. It is also to be noted that force-dynamics was recognized and adopted as fundamental force interactions in the therapeutic practice introduced by Sigmund Freud.

Outside the physical, perhaps the most familiar application [of force-dynamic principles] is that of Freud to the psyche, with such psychodynamic concepts as libido and drives, repression and resistance, id-superego conflict, and a tensionreduction model for restoring equilibrium. (Talmy 2000a : 410.)

In summary it can be stated that force-dynamics appears as a fundamental notional system which structures conceptual material that pertains to force interaction to become manifest on many linguistic levels, such as the physical, psychological, social, inferential, discourse, argumentation, mental-space blending, reference or projection.

\subsection{The cognitive culture system and the language-culture parallelism by Leonard Talmy}

Having given ample attention to the linguistic representation of conceptual structure, Talmy offers a profound analysis of conceptual organization in culture in (Talmy 2000b) too. Talmy offers an evolutionary perspective on the cognitive language system and presumes and acknowledges the evolutionary advantage of a high-level and complex cognitive systems termed cognitive language system with specific linguistic structure and linguistic meaning characterizing natural languages. In a similar vein, Talmy offers an evolutionary perspective on the cognitive culture system and assumes the evolutionary advantage for human communities which have developed a high-level and complex cognitive system termed cognitive culture system with specific cultural behavioral patterns, 
social structures and social practices. Talmy advocates individual-based cultural cognition just as he does with individual-based linguistic cognition assuming that neither of these cognitive systems has autonomous existence beyond the cognition of the individual humans. The functions of the cognitive culture system include the acquisition, exercise, maintenance, transmission and imparting of culture. Further, cultural cognition presumes an innately determined brain system to guide the development of cultural patterns through the existence of cognitive organization in individuals who collectively make up a society. Cultural patterns are the content of this highly differentiated and systematically structured cultural complex which pertains to both the conceptualaffective patterns and the behavior patterns internalized by the individual humans belonging to given cultural-social groups.

The cognitive culture system within an individual assesses the conceptual-affective and behavioral patterns that it sees others exhibit, as well as attending to instruction on such patterns, and internalizes what it has abstracted from this assessment and instruction. It performs the process of assessment in a highly structured way. The process includes determination of the outside groups most relevant to the self, abstraction across the members of each such group, attention to only certain categories of phenomena manifested by those members, and resolution of conflicts among the patterns of different groups. [...] The cognitive culture system implements the cultural patterns it has acquired, both to produce them and to comprehend new instances of production by others. (Talmy 2000b : 374)

The parallelism between the linguistic and the cultural cognitive systems may arise from their evolutionary history. Probably these were the last two cognitive systems to have coevolved interactively, presumably conditioned by other cognitive systems (e.g. perception in different modalities: visual and kinesthetic, memory, attention, causal reasoning, inferencing, abstraction, planning, anticipatory projection, mental-state attribution to others, etc.) already in use.

We can note here that, of all the cognitive systems, only language and culture extensively exhibit patterns of a universal abstract structure underlying a variability of instantiation determined by the social group (i.e. various particular languages and cultures. Despite such parallelism, though, language and culture have evolved as distinct cognitive systems. (Talmy 2000b : 377)

\subsection{Narrative structure as a pattern-forming cognitive system by Leonard Talmy}

21 The research on cognitive systems suggests that they might be distinct, however, are not autonomous complexes by any means. Human cognition is a complex way of mental life in which the interaction of different cognitive systems, cognitive skills and competences is imperative. Talmy has offered the recognition and analysis of yet another comprehensive framework which makes the production and comprehension of narratives possible. In the center of this comprehensive cognitive system is "narrative work" with the participation of "sentient entities". Narratives can be stories, histories, cultural narratives, discourse narratives, life narratives, etc. that presuppose the existence of individual minds that produce the narratives as well as minds that cognize the narratives, exerting both generative and interpretative mental abilities. The "narrative work" requires a particular chunk of space and time and a society of minds (sentient entities) that have assembled the narrative and have perceived and cognized it as such. Thus, a 
narrative requires a cognizant producer and a cognizant perceiver in a concrete narrative work. However, Talmy argues - with his phenomenological orientation - for a generic case that opens up new perspectives on the conceptual organization in human cognition.

An intentional sentient producer is not strictly necessary for the construal of something as a narrative. A perceiving mind by itself is capable of experiencing some naturally occurring formation or some unintended formation by a sentient entity, as being a narrative work. More systematically, a perceiver regularly construes the external events she has witnessed over a period of time as narrative a type that might be termed "history". And a perceiver regularly construes the sequence of personal experiences he has had over time - both interior and externally based experiences - as constituting a narrative, that of his "life". (Talmy 2000b : 418)

Thus, the narrative work can be seen as a pattern-forming cognitive system which consists of a set of mental capacities that interact with each other to perform a particular integrated and coherent mental construal. In other words, the function of a narrative cognitive system is to interconnect an assembly of mental experiences in order to form a single overall pattern called "narrative". Talmy's analysis further supports the evolutionary perspective when he argues for a selective pressure in the evolution of the narrative. In his view, the application of the narrative cognitive system to temporal sequence may have evolved through selective pressure to bring about great scope and attention attraction to facilitate the cognizing of larger patterns and longer-range plans. Also, we have to note here that narratives are not void of cultural context: cultures and subcultures constitute a relatively coherent cognitive system which in turn can affect and determine particular sets of narrative characteristics. Thus, the narratives will reflect the conceptual structure, the affective structure, the presuppositions, the values and in general the "world-view" of the individuals producing or experiencing the narratives.

\section{A short comparison of Raccah and Talmy}

In the previous sections I made an attempt to understand and interpret the use and intended meanings of the terms "semantics", "semantic object", "cognitive object" and "inter-subjective experience" in Pierre-Yves Raccah's semantic theory and in Leonard Talmy's theory of cognitive semantics. Two central notions have crystallized in the survey : that of constraint and that of objective versus subjective content, respectively.

In Raccah's analysis semantics (especially with its lexical semantic structure) can and does constrain as an objective content linguistic meaning. As an irrevocable consequence, it can affect utterance interpretation and exert perceptual bias on it, reflecting intersubjective elements and ideological commitments in the interpretation-patterns. In his view, human expertise (interpretative competence included) strongly relies on beliefs and knowledge of the linguistic community which is ultimately and fundamentally constrained by linguistic structure. As we have seen above, part of linguistic structure is semantic structure which imposes biases on denotation. It is not clear, however, in Raccah's discussion where the "objective content" of semantic structure of lexical items and certain grammatical constructs that impose constraints on meaning-creation and utterance interpretation come from.

In Talmy's analysis the role of semantics in shaping linguistic meaning is decisive and constitutive by effect of imposing constraints on conceptual organization (general conception) in language. Semantics concerns itself with content experienced in 
consciousness, content both ideational (concept-based) and affective (based on emotional states) and perceptual. The phenomenological conception of cognitive semantics assumes accessibility to the subjective contents of consciousness in shaping linguistic meanings, and ultimately, organizing conceptual structure in language. In short, cognitive semantics for Talmy is conceptual content and its structure specifically designed for natural language. Semantics exerts very strong constraints on linguistic structure and interpretation due to the fact that semantic structure manifests itself exclusively as objectified conceptual structure for human language.

Taking into consideration the central claims of Talmy's cognitive semantics theory, I suggest a reasonable reconciliation of the two conceptual proposals. If I understand well, Raccah considers "the formal aspects" of linguistic analysis as objective and noncognitive and "the conceptual aspects" as inter-subjective and cognitive. Talmy acknowledges the interaction of the formal, the psychological and the conceptual, however, he considers all these aspects as belonging to the cognitive realm of human mental activities facilitating social, cultural and linguistic cognition.

\section{Challenges in the Digital Age}

The Digital Age has invented new ways of collecting and processing information for human beings (and other intelligent, reasoning entities as well) in all societies on the globe regardless of social and political order or ideological commitment. At the same time, it has become imperative for researchers to develop new ways of thinking about and understanding digital culture which has generated novel aspects of digital literacy, information processing, social cognition, learning techniques and knowledge management.

In the present section I intend to reflect on some of the converging findings in my research in the fields of cognitive linguistics and cognitive anthropology. I will, however, limit the scope of my survey to the topic of cultural conceptualization manifested in cultural narratives in order to be able to shed light on a paradigm change in social cognition induced by digital culture.

In the first part of my study I followed my interest in the quest for the origins (ontological and epistemic sources) of lexical meanings, linguistic meanings, utterance meanings and contextualized discursive meanings. It seems to me inevitable that one finds "general conception" (i.e. thought) together with patterns and techniques of conceptualization as an overarching environment. This is why the identification of cultural cognition and lingusistic cognition seems to be a viable theoretical option. Further, it seems to have been an important claim in the study of human meaningcreation that coordinated and consensus-based interpretation patterns can be bound to the notion "lifeworlds" in which verbal and non-verbal behavior can be assessed and interpreted in a seamless way based on the existence of "narrative work" across human cultures. To this end, I find the semantic theory of Pierre-Yves Raccah and the cognitive semantics theory of Leonard Talmy ground-breaking and convergent toward the understanding of sense-creation and interpretation mechanisms in human language. In the following section I intend to confront our solid acquaintance with the foundations of linguistic cognition and cultural cognition with a different type of meaning-creation uder the conditions of a highly dynamic information exchange and collateral information sharing environment emerging in digital culture in the Digital Age. 
30 My analysis has been triggered by the observation that unprecedented development and innovation in information and communication technologies have exerted unforeseen impact on social cognition, information processing and human learning. I make an attempt to identify the observable causes of the paradigm change in social cognition by arguing that the long evolutionary process of linear information processing constituting narrative-like mental structures based on cultural conceptualizations of any culturally coherent human community has already been challenged by parallel and connected network-based information processing making use of fragmented, encapsulated information chunks provided by a plethora of information sources. It is also claimed that traditional learning conditions were constituted by a hierarchically-determined distribution of knowledge and information and by a norm-based culture of behavior patterns. In opposition to the traditional learning conditions, the emerging patterns of digital cognition, digital information management and digital literacy are not only faster involving greater complexities, but they also facilitate coping with virtualization in general, leading to new cultural landscapes involving augmented reality. The new phenomenon is acknowledged and analyzed in (Komlósi and Waldbuesser 2015) in which we create a term Connected Cognitive Entity Generation (CCE Generation) referring to the participants of the new information management practices induced by the very nature of the digitalized information environment. We observe that the EECs seem to have finally broken out of the hierarchically structured, authoritative knowledge distribution due to the unprecedented advancement and development of the digital technologies. As opposed to Generation X or Generation Y, CEEs constituting the digital space as "digital natives" will continually generate connected cognitive entities that will no longer be confined to generating a demographically conceived population. They will be social actors as interacting cognitive entities.

31 We must acknowledge that cognitive entities in the digital environment are related to each other not by commonly shared cultural narratives (as stated in the tenets of cognitive cultural anthropology) but by random interest in networking, information sharing and emergent cognition. One should also realize that this type of networked information exchange is not teleology-driven. What we witness under such conditions is an exponential growth of potential information sources due to the parallel design of connections.

\section{Mainstream cultural linguistics and cognitive anthropology on cultural conceptualization manifested in cultural narratives}

32 I propose a brief comparison between two fascinating fields of research fundamentally committed to knowledge management in the social space. On the one hand, I will refer to current tenets of cognitive anthropology by discussing the concept of cultural conceptualizations and situated cognition manifest in socially situated discourse (Frank 2008) and the concept of distributed cultural conceptualizations and emergent cultural cognition (Sharifian 2003, 2008, 2011). On the other hand, I will survey the concept of digital communication environments creating augmented virtual realities (Siegemund 2004; Abrash 2014) and the concepts of cognitive entity generation (Komlósi and Waldbuesser 2015). 


\subsection{Collectively constituted linear narratives with commonly shared interpretation patterns} community can be perceived as a mental framework providing a virtual fabric of a cohesive narrative to accommodate and determine culture-specific interpretation schemes for the members of cultural groups. Frank (2008) describes sociocultural situatedness as a vital interaction of the individual mind with social and cultural structures (such as other agents, artifacts, conventions, etc., in short, tangible and intangible cultural participants), thus facilitating social cognition involving learning, socialization, collective memory, mental maps of events, norms and patterns of behavior. Although the nature of the interaction in the theory of sociocultural situatedness is not spelled out in detail, one cannot fail to observe the quintessence of situated cognition: the socio-cognitive involvement of the individual mind is realized via interactions with other individual minds and with other social and cultural entities where the community of individual minds collectively creates cohesive and supportive narratives in the course of these interactive processes.

No wonder, the foundational philosophical tradition established by Habermas's consensus-seeking communicative acts (Habermas 1994) comes to mind at this point. His starting claim is that discourse has a socially situated nature which determines and restricts communication as an interactive meaning-creating activity to be realized within the horizon of shared, unproblematic convictions which automatically constitute consensus-generating interpretative patterns (Habermas 1994: 66). It entails - at the same time - that communicative actors are always moving within the horizon of their lifeworlds since they cannot step outside of it. Lifeworld is the invisible and indispensable background of everything we do and of everything we are.

Frank (2008) identifies the outcome of the community of "lifeworlds" which are the results of fairly homogeneous cultural conceptualizations as follows : their manifestation is a culturally transmitted and linguistically organized stock of interpretative patterns. Lifeworld can be understood as a kind of non-thematic knowledge that is characterized by an unmediated certainty and a holistic constitution. It is composed of cultural patterns, legitimate social orders and personality structures, forming complex contexts of meaning.

arifian (2003) proposes a complex theory of cultural conceptualizations that function as collective representations to secure permanence in culture. This process, however, is dynamic and highly interactive within a cultural community as conceptualizations are represented in a distributed fashion across the minds of a cultural group. Cultural dynamics manifests itself in discourse the condition of which are bound to be permanently modified as the members negotiate and renegotiate these conceptualizations across generations. It is important to distinguish between the terms narrative and discourse. In Sharifin's theory of distributed, emergent cultural cognition (Sharifian 2008, 2011) collective narratives secure permanence in culture while discursive processes permit the renegotiation of cultural conceptualizations across generations. It is a novelty in the formulation that renegotiated and augmented cultural narratives reveal emergent properties in the flow of cultural interactions. Sharifian's dialectically integrative view sees cognition as a complex adaptive system that emerges from the

Corela, HS-19 | 2016 
interactions between the actors of a cultural group who negotiate and renegotiate their emergent cultural cognition across time and space. Although this theory offers an interesting perspective on augmented cultural narratives that overarch generations, it does not explain what exactly guarantees permanence in collective cultural representations.

It is important to emphasize that collectively created cultural narratives have had their decisive function in shaping social cognition and social behavior across generations functioning in a linear mode of information processing. These narratives - as results of the complex adaptive cognitive systems of the members - have been successful in creating culturally controlled and augmented realities by allowing interaction and renegotiation of emergent cultural cognition. These cultural competences enabled, orientated and encouraged members of the cultural group to cope with hierarchically-built, conceptually-derivable and ideologically-driven meaning structures, to develop binding forces of cultural belonging and to seek permanent roles in given hierarchical structures.

In the light of research on digital culture, I intend to question and challenge Sharifian's theory that supports an integrative view of social cognition based on homogeneous cultural conceptualizations. My own research suggests that permanence in collective cultural representations cannot be secured under the circumstances of contemporary digital environments which produce a plethora of fragmented narratives due to the alternative, parallel mode of information processing. Digital culture enables cognitive entities in the digital environment to cope with network-generated, associative meaning structures and to make sense of fragmented narratives and emergent contexts.

\subsection{Fragmented narratives in digital communication}

The notion of narrative work was introduced in association with contextualization in connection with which we also acknowledge that context-building and contextidentification figure as special creative mental activities. (Komlósi 2010, 2012) offer an analysis of a systematic hierarchical relationship between foundational settings, ontological commitments and epistemic states in connection with contextualization :

1. Situations and faithful mappings of situations ;

2. Contextualized situations (selective mental representations of situations) ;

3. The linguistic context (texts and discourse depicting contextualized situations);

4. The pragmatic contexts (constructed contexts based on users' perspectives) ;

5. The context of social interaction and culture (social reality, knowledge of others) ;

6. The context of the self (figuring in individual and social cognitive situations);

7. Instantiated mental contexts (situated language use) ;

8. The context of the web-experience (cognition in virtual reality).

We can see that (1-2) manifest situational contexts, (3) represents a linguistic context and (4-8) realize mental contexts. Social interactive skills require and entail those higher level cognitive skills that facilitate adaptive, context-sensitive interpretations. Here we have to observe that social cognition is a cover term for a vast number of different cognitive activities responsible for information processing and knowledge management with relative independence of the types of informational inputs. A mental context is constructed out of selected properties of mental contents, thus serving as background for evaluating the meaningfulness of particular arrangements in information structure. Linguistic 
structure in itself is not sufficient to determine contextual meaning. A mental context yields added value with which linguistic meaning is to be complemented.

A good number of contemporary research suggest that we are experiencing a new paradigm in perceiving, conceiving and managing information, especially with those people who have been socialized in the digital era and have internalized the very nature of digital culture. The members of the digital community function in connected networks created by a number of different types of cognitive entities. These people are cognitive entities themselves who feel at ease with digitalization and virtualization (Siegemund 2004 ; Abrash 2014). In their environments all sorts of smart devices are at their disposal such that they can cope with a plethora of information and can communicate effectively in accordance. We can assert today that these social actors function as cognitive entities. The notion cognitive entity (Komlósi and Waldbuesser 2015) encompasses both human and non-human agents, digital and mechanical entities that behave smartly and who / which are presumed to exist within a highly interlocked framework of a multi-channel information flow and exchange.

In the case of the community of cognitive entities we talk about chunks of information that might be seen as fragmented narratives, rather than about collectively constituted cultural narratives. Any piece of information can be related to any other information by creating suitable or agreeable contexts for interpretation. Therefore, we can still envisage information chunks that might fit into narratives of some sort. However, the narratives created on-line are not based on negotiation, let alone renegotiation. They are results of non-deterministic interpretations, accepted for current states of affairs. These information chunks might be ephemeral and seemingly arbitrary. Creating contexts for interpretation means an innovative challenge for the interactive agents. Fragmented narratives become flexible building-blocks for novel contexts. As opposed to cultural narratives which are based on cultural conceptualizations and are linear in design, fragmented narratives are non-linear, non-deterministic and distributed in a parallel design.

\section{Conclusions : fragmented but permanently connected information management}

43 What we have seen as the main argument of our research is that we see digital culture as a novel environment for social cognition that inevitably undermines the permanence of cultural narratives. Instead, cognitive entities seek connection to each other in a parallel but non-deterministic fashion in order to exploit the immense potential in a plethora of information sources. The consequences for the nature and mechanisms for social cognition based on digital culture cannot be predicted reliably as of today. A new perspective on and an unprecedented practice of information management is, however, part of an irreversible process. 


\section{BIBLIOGRAPHIE}

Abrach Michael, "What VR could, would, and certainly will be within two years". [http:// media.steampowered.com/apps/steamdevdays/slides/vrshouldbe.pdf. Downloaded 30.01.2016].

Frank Roslyn M., "Introduction : Sociocultural Situatedness", in Frank Roselyn M., Dirven René, Ziemke Tom and Bernárdez Enrique (eds.), Body, Language and Mind. Sociocultural Situatedness, vol. II, Berlin - New York, Mouton de Gruyter, 2008, pp. 1-18.

Habermas Jürgen, "Actions, speech acts, linguistically mediated interactions and the lifeworld", in Fløistad Guttorm (ed.), Philosophical Problems Today, vol. 1, Dordrecht - Boston, Kluwer, 1994, pp. 45-74.

Komlósi László Imre, "In Quest of Cultural and Conceptual Universals for Situated Discursive Practice", in Komlósi László Imre, Houtlosser Peter and Leezenberg Michiel (eds.), Communication and Culture: Argumentative, Cognitive and Linguistic Perspectives, Amsterdam, SicSat, 2003, pp. 159-176.

Komlósi László Imre, "Hidden Effects of Presumptive Arguments on Argument Assessment Strategies”, in Houtlosser Peter and Rees Haft-van (eds.), Considering Pragma-Dialectics. A Festschrift for Frans H. van Eemeren on the Occasion of his $60^{\text {th }}$ Birthday, Mahwah, N.J. - London, Lawrence Erlbaum Associates, 2006, pp. 175-183.

Komlósi László Imre, “Perelman’s vision : Argumentation schemes as examples of generic conceptualization in everyday reasoning practices", in Eemeren Frans H. van, Blair J. Anthony, Willard Charles A. and Garssen Bart (eds.), Proceedings of the Sixth Conference of the International Society for the Study of Argumentation, Amsterdam, SicSat, 2007, pp. 789-796.

Komlósi László Imre, “Contextualization and Cognitive Synergism. The Interaction of Ontology and Epistemology in the Interpretation of Contexts", in Hölker Klaus und Marello Carla (Hrsg), Dimensionen der Analyse von Texten und Diskursen / Dimensioni dell'analisi di testi e discorsi. Festschrift für János Sándor Petöfi zum achtzigsten Geburtstag / Festschrift per János Sándor Petöfi in occasione del suo ottantesimo compleanno, Berlin - London - Zürich - Wien, LIT Verlag, 2011, pp. 186-203.

Komlósi László Imre, “Linguistic Context, Pragmatic Context, Mental Context : Meaning Construction and Interpretation via Contextualization", in Dontcheva-Navratilova Olga and Povolná Renata (eds), Discourse Interpretation: Approaches and Applications, Newcastle upon Tyne, Cambridge Scholars Publishing, 2012, pp. 19-38.

Komlósi László Imre, "Cognitive and effective material in the Mental Lexicon : The interface of form and meaning”, Argumentum n ${ }^{\circ}$ 9, 2013, pp. 223-233. [http://argumentum.unideb.hu/angol/ archive.html\#9_(2013). Downloaded 30.01.2016].

Komlósi László Imre, "Digital literacy and the challenges of digital technologies for human learning”, in Dejica Daniel, Gyde Hansen and Sandrini Peter (eds.), Humanities, Language and the Digital Era: Challenges and Perspectives, Berlin, Walter de Gruyter, 2015. [http://www.amazon.ca/ Language-Digital-Era-Challenges-Perspectives/dp/311047204X. Downloaded 30.01.2016].

Komlósi László Imre, "Challenges for the traditional role of cultural conceptualizations for social discourse in the Digital Era”, in Kačmarova Alena and Shatro Bavjola (eds.), Language, Literature 
and Culture in a Changing Transatlantic World, Newcastle upon Tyne, Cambridge Scholars Publishing, 2016 (to appear).

Komlósi László Imre and Patrick Waldbuesser, “The Cognitive Entity Generation : Emergent Properties in Social Cognition", in Baranyi Peter (ed.), Proceedings of the $6^{\text {th }}$ International IEEE Conference on Cognitive Infocommunications (CogInfoCom2015), Piscataway - Budapest, IEEE, 2015, pp. 214-221.

Raccah Pierre-Yves, "What is an empirical theory of linguistic meaning a theory of ?", in Frajzyngier Zygmunt, Hodges Adam and Rood David S. (eds.), Linguistic Diversity and Language Theories, Amsterdam - New York, John Benjamins, 2005, pp. 51-80.

Raccah Pierre-Yves, "Points of view and argumentation : Semantics as an empirical science", Proceedings of the $6^{\text {th }}$ Conference of the International Society for the Study of Argumentation, Amsterdam, SicSat, 2007, pp. 1085-1093.

Raccah Pierre-Yves, “A semantic structure for points of view : about linguistic constraints on argumentation", Proceedings of the $7^{\text {th }}$ Conference of the International Society for the Study of Argumentation, Amsterdam, SicSat, 2011, pp. 1596-1604.

Raccah Pierre-Yves, "Linguistic argumentation as a shortcut for the empirical study of argumentative strategies", in Eemeren Frans H. van and Garssen Bart (eds.), Reflections on Theoretical Issues in Argumentation Theory, Cham- Heidelberg - Dordrecht - New York, Springer International Publishing Switzerland, 2015, pp. 279-293.

Sharifian Farzad, "On cultural conceptualizations", Journal of Cognition and Culture vol. 3, n 3, Leiden, Koninklijke Brill NV, 2003, pp. 187-207.

Sharifian Farzad, "Distributed, emergent cultural cognition, conceptaulisation and language", in Frank Roselyn M., Dirven René, Ziemke Tom and Bernárdez Enrique (eds.), Body, Language and Mind. Sociocultural Situatedness, vol. II, Berlin - New York, Mouton de Gruyter, 2008, pp. 241-268. Sharifian Farzad, Cultural Conceptualization and Language, Amsterdam, John Benjamins, 2011. Siegemund Frank, Cooperating Smart Everyday Objects - Exploiting Heterogeneity and Pervasiveness in Smart Environments, PhD dissertation, Zürich, Swiss Federal Institute of Technology Zurich (ETH Zurich), 2004. [http://www.vs.inf.ethz.ch/publ/papers/diss-siegemund-final-small.pdf. Downloaded 30.01.2016].

Talmy Leonard, Toward a Cognitive Semantics, vol. I : Concept Structuring Systems, [A Bradford Book], Cambridge, MA / London, The MIT Press, Chapter 7 : Force Dynamics in Language and Cognition, 2000a, pp. 409-470.

Talmy Leonard, Toward a Cognitive Semantics, vol. II : Typology and Process in Concept Structuring, [A Bradford Book], Cambridge, MA / London, The MIT Press, 2000b, Chapter 7 : The Cognitive Culture System, pp. 373-415, Chapter 8 : A Cognitive Framework for Narrative Structure, pp. 417-482.

\section{NOTES}

1. The latter one is presented as shared knowledge of the speaker and the hearer and reveals the ideology and cultural background within which the interlocutors rest (cf. 'discourse' and encapsulated ideologies). 


\section{RÉSUMÉS}

Cette étude se compose de deux parties, au premier abord disparates, mais en réalité étroitement liées. La première traite de deux théories sémantiques fondamentales qui ont en point commun les contraintes sémantiques des langues humaines. Celle que Pierre-Yves Raccah propose assigne un caractère objectif à des contraintes incluses dans la structure de la langue, qui pèsent sur l'interprétation du sens des énoncés. La sémantique cognitive de Leonard Talmy met en œuvre la manifestation spécifiquement linguistique du concept inclus dans la structure de la cognition linguistique. Pour réconcilier les deux positions, nous proposons de revisiter la notion de " contraintes sur la construction du sens ». La seconde partie vise à faire le point des nouveaux enjeux imposés par la culture numérique qui, comportant des mutations profondes, bouleverse les pratiques de la cognition sociale. Nous mettrons en évidence que la construction du sens et les techniques d'apprentissage dans l'ère numérique ne produiront que des structures narratives non-linéaires et la cognition linguistique semble perdre tout son fondement pour établir des schémas d'interprétation stables et consensuels.

The present study consists of two, seemingly disparate but not incongruous parts. The first part discusses two ground-breaking semantic theories whose common theme is semantic constraints on natural language. Pierre-Yves Raccah's semantic theory discusses the direct and objective contribution of semantic objects in linguistic structure which takes effect in imposing constraints on the interpreted senses of utterances. Leonard Talmy's cognitive semantics assumes semantics to be a language specific manifestation of concept structuring in linguistic cognition. A possible platform for reconciliation between the two views on semantics is offered by re-conceptualizing the notion "constraints on meaning construction". The second part of the study aims at pointing at the emerging novel conditions provided by digital culture which may lead to fundamental changes in the practices of social cognition. The discussion raises the issues of meaning-creation and learning techniques in the digital era as traditional cultural narratives tend to become fragmented and linguistic cognition seems to lack the unquestionable common ground for negotiated and consensual patterns of interpretation.

\section{INDEX}

Keywords : empiricity for semantics, constraints on meaning construction, semantic constraints utterance meaning, language-culture parallelism, cultural conceptualizations, fragmented narratives

Mots-clés : empirisme en sémantique, contraintes, construction du sens, effets de sens, langueculture, conceptualisation culturelle, narration non-linéaire

\section{AUTEUR}

\section{LÁSZLÓ I. KOMLÓSI}

Széchenyi István University, Győr, Hungary 